\title{
The fossil record of early tetrapods: worker effort, and the end-Permian mass extinction
}

\author{
Emma L. Bernard, Marcello Ruta, James E. Tarver, and Michael J. Benton \\ Acta Palaeontologica Polonica 55 (2), 2010: 229-239 doi: http://dx.doi.org/10.4202/app.2009.0025
}

It is important to understand the quality of the fossil record of early tetrapods (Tetrapoda, minus Lissamphibia and Amniota) because of their key role in the transition of vertebrates from water to land, their dominance of terrestrial faunas for over 100 million years of the late Palaeozoic and earlyMesozoic, and their variable fates during the end-Permian mass extinction. The first description of an early tetrapod dates back to 1824 , and since then discoveries have occurred at a rather irregular pace, with peaks and troughs corresponding to some of the vicissitudes of human history through the past two centuries. As expected, the record is dominated by the well-sampled sedimentary basins of Europe and North America, but finds from other continents are increasing rapidly. Comparisons of snapshots of knowledge in 1900, 1950, and 2000 show that discovery of new species has changed the shape of the species-level diversification curve, contrary to earlier studies of family-level taxa. There is, however, little evidence that taxon counts relate to research effort (as counted by numbers of publications), and there are no biasing effects associated with differential study of different time intervals through the late Palaeozoic and Mesozoic. In fact, levels of effort are apparently not related to geological time, with no evidence that workers have spent more time on more recent parts of the record. In particular, the end-Permian mass extinction was investigated to determine whether diversity changes through that interval might reflect worker effort: it turns out that most records of early tetrapod taxa (when corrected for duration of geological series) occur in the Lower Triassic.

Key words: Discovery curve, collector curve, basal tetrapods, fossil record, Tetrapoda, Temnospondyli, Lepospondyli, end-Permian mass extinction.

Emma Bernard [emma.bernard121@googlemail.com], Marcello Ruta [․․ruta@bristol.ac.uk ], James E. Tarver [james.tarver@bristol.ac.uk], Michael J. Benton (corresponding author) [mike.benton@bristol.ac.uk], Department of Earth Sciences, University of Bristol, Bristol, BS8 1RJ, UK. 
This is an open-access article distributed under the terms of the Creative Commons

Attribution License (for details please see creativecommons.org), which permits unrestricted use, distribution, and reproduction in any medium, provided the original author and source are credited.

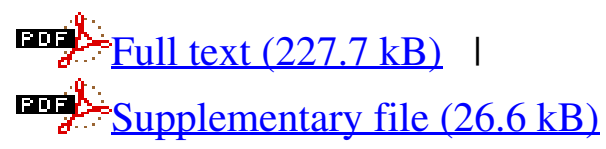

